\title{
Penerapan Strategi Brain-Based Learning Berbantuan Geogebra terhadap Kemampuan Berfikir Kreatif Siswa
}

\author{
Suci Lupita Sari ${ }^{*}$, Destia Wahyu Hidayati ${ }^{2}$, Arie Wahyuni ${ }^{3}$, \\ 1,2,3 Universitas Ivet \\ *sucilupitasari@gmail.com
}

\begin{abstract}
ABSTRAK
Tujuan penelitian ini adalah untuk mengetahui rata-rata kemampuan berfikir kreatif matematika siswa dengan menggunakan strategi Brain-Based Learning berbantuan Geogebra lebih dari KKM (70) dan untuk mengetahui rata-rata kemampuan berfikir kreatif matematika siswa dengan menggunakan strategi Brain-Based Learning berbantuan Geogebra lebih tinggi dari kemampuan berfikir kreatif matematika siswa dengan menggunakan cara konvensional. Penelitian ini menggunakan metode kuantitatif. Sampel penelitian ini adalah siswa kelas VIII-A sebanyak 16 siswa sebagai kelas eksperimen dan kelas VIII-B sebanyak 18 siswa sebagai kelas kontrol. Hasil penelitian ini menunjukkan bahwa kemampuan berfikir kreatif siswa dengan menggunakan strategi Brain-Based Learning berbantuan Geogebra lebih dari 70 serta ada perbedaan yang signifikan antara kemampuan siswa yang memperoleh pembelajaran secara konvensional dengan siswa yang memperoleh pembelajaran dengan model Brain-Based Learning Berbantuan Geogebra.
\end{abstract}

Kata Kunci: Brain-Based Learning, Geogebra, Kemampuan Berfikir Kreatif.

\section{ABSTRACT}

The purpose of this study is to determine the average mathematical creative thinking ability of students by using Geogebra-assisted Brain-Based Learning strategies more than KKM (70) and to find out the average mathematical creative thinking ability of students using more Brain-Based Learning strategies assisted by Geogebra higher than students' creative mathematical thinking abilities using conventional methods. This research uses quantitative methods. The sample of this study was students of class VIII-A as many as 16 students as the experimental class and class VIII$B$ as many as 18 students as the control class. The results of this study indicate that students' creative thinking abilities using Geogebra-assisted Brain-Based Learning strategies are more than 70 and there are significant differences between the abilities of students who obtain conventional learning with students who learn with the Geogebra-Aided Brain-Based Learning model.

Keywords: Brain-Based Learning, Geogebra, Creative Thinking Ability. 


\section{PENDAHULUAN}

Matematika merupakan salah satu pelajaran yang membutuhkan cukup banyak waktu agar materi dapat tersampaikan dengan baik. Siswa-siswa menganggap matematika sebagai pelajaran yang paling menakutkan di antara mata pelajaran yang lain. Matematika dianggap sebagai sumber kesulitan dan hal yang paling dibenci dalam proses belajar di sekolah. Ketidaksenangan dalam suatu mata pelajaran berpengaruh terhadap keberhasilan proses pembelajaran karena ketidaksenangan akan membuat siswa malas dan enggan untuk belajar. Secara tidak langsung berpengaruh pada cara berfikir kreatif siswa.

Berdasarkan pengamatan sebelumnya yang dilakukan pada tanggal 12 Desember 2018 di MTs An-Nur Kedungtuban Kabupaten Blora, guru mata pelajaran matematika masih menerapkan model pembelajaran konvensional, yaitu pembelajaran yang berpusat kepada guru. Seharusnya dalam proses pembelajaran, guru bukan sebagai satu-satunya sumber belajar. Guru sering menggunakan metode ceramah dalam penyampaian materinya. Pembelajaran matematika yang diajarkan dengan model pembelajaran konvensional kurang menarik minat dan perhatian siswa. Kurangnya minat dan perhatian siswa pada pelajaran matematika membuat siswa kurang berfikir kreatif dalam mata pelajaran matematika yang membuat hasil belajar siswa kurang memuaskan, sehingga sebagian siswa menganggap pelajaran matematika merupakan pelajaran yang sulit.

Rakhmad (2005), menyatakan bahwa belajar itu harus berbasis otak, dengan kata lain revolusi belajar dimulai dari otak. Sebenarnya para guru telah menyadari bahwa pembelajaran berfikir membuat anak menjadi cerdas, kritis, dan kreatif serta mampu memecahkan masalah yang berkaitan dengan kehidupan mereka sehari-hari adalah hal yang penting. Kesadaran ini juga telah mendasari pengembangan kurikulum yang kini lebih mengedepankan pembelajaran kontekstual. Menurut Lestari (2014) Pembelajaran Brain-based Learning yang merupakan sebuah konsep pembelajaran yang dikembangkan secara alamiah dalam pemberdayaan otak mempunyai tiga strategi utama yang dapat di kembangkan dalam pelaksanaan pembelajaran.

Berbagai manfaat program komputer dalam pembelajaran matematika dikemukakan oleh Kusumah (2003), yaitu program-program komputer sangat ideal untuk dimanfaatkan dalam pembelajaran konsep-konsep matematika yang menuntut ketelitian tinggi, konsep atau prinsip yang repetitif, penyelesaian grafik secara tepat, cepat dan akurat. Kusumah (2003) juga mengemukakan bahwa inovasi pembelajaran dengan bantuan komputer sangat baik untuk diintegrasikan dalam pembelajaran konsep-konsep matematika, terutama yang menyangkut transformasi geometri, kalkulus, statistika, dan grafik fungsi. Peneliti memilih aplikasi Geogebra karena melihat karakteristik siswa SMP yang suka dengan konsep mengaplikasikan karya dengan cara berfikir kreatif siswa. Geogebra berfungsi sebagai media gambar. Secara umum, geogebra akan memberikan pengalaman langsung kepada siswa dalam belajar. Dengan demikian, diharapkan dapat meningkatkan berfikir kreatif dari siswa, karena geogebra berperan sebagai media yang digunakan untuk menyampaikan materi kepada siswa.

Kemampuan berfikir kreatif adalah kemampuan siswa dalam memecahkan masalah suatu

permasalahan yang sifatnya terbuka dengan memunculkan gagasan ataupun ide-ide baru yang tidak baku atau bersifat fleksibel, siswa yang terlibat aktif mengikuti pembelajaran di kelas memiliki hasil pembelajaran yang memuaskan (Putra \& Purwasih, 2015). Menurut Wahyuni \& Kurniawan (2018) kemampuan berfikir kreatif merupakan kemampuan yang memberikan ide- 
ide kepada mahasiswa sesuai dengan kelancaran, keluwesan, keaslian dan merinci. Kefasihan ditunjukkan dengan kemampuan sejumlah besar gagasan pemecahan masalah secara lancar dan cepat. Keluwesan mengacu pada kemampuan untuk menemukan gagasan yang berbeda-beda dan luar biasa untuk memecahkan suatu masalah.

\section{METODE}

Penelitian yang dilakukan menggunakan penelitian kuantitatif. Penelitian ini dilakukan pada bulan juni 2019, populasi dalam penelitian ini adalah seluruh siswa kelas VIII MTs AnNur Kedungtuban Kabupaten Blora tahun 2018/2019. Penentuan sampel di lakukan dengan cara kelompok (cluster random sampling) yaitu pengambilan sampel secara acak yang di dasarkan kepada kelompok, bukan di dasarkan kepada anggota-anggotanya (Ruseffendi, 2005). Sampel yang di gunakan pada penelitian ini sebanyak dua kelas yang di ambil secara acak, kelas eksperimen adalah kelas yang diajar menggunakan Brain-Based Learning berbantuan Geogebra kelas kontrol adalah kelas yang diajar menggunakan cara konvensional.

\subsection{Prosedur Penelitian}

Sebelum peneliti melaksanakan penelitian, peneliti membuat instrumen penelitian kemudian divalidasikan ke validator I dan validator II. Setelah soal divalidasi, peneliti melakukan tes uji coba di kelas uji coba kemudian peneliti siap melaksanakan penelitian. Hasil uji coba kemudian dilakukan pengujian validitas, reliabilitas, daya pembeda dan tingkat kesukaran. Penelitian yang dilakukan peneliti yaitu proses pertama peneliti mengajar secara konvensional di kelas kontrol. Peneliti menggunakan Brain-Based Learning berbantuan Geogebra dalam mengajar di kelas eksperimen. Pengukuran kemampuan berfikir kreatif siswa menggunakan soal pretest dan soal posttest. Soal pretest diberikan saat pertama kali pertemuan dan soal posttest diberikan pada saat akhir pembelajaran.

Sebelum melakukan analisis uji kesamaan dua rata-rata terhadap data nilai, perlu dilakukan uji prasyarat terlebih dahulu, yaitu uji normalitas dan uji homogenitas data. Apabila data berdistribusi normal, maka pengujian hipotesis dilakukan dengan statistika parametrik, tetapi apabila data berdistribusi tidak normal, maka pengujian hipotesis dilakukan dengan menggunakan statistika non parametrik. Hasil yang sudah dilakukan uji normalitas dan homogenitas kemudian dilakukan uji one sample t test dan uji t.

\subsection{Desain Penelitian}

Kegiatan pertama pada penelitian yang dilakukan di kelas eksperimen pertama kali yaitu pra-pemaparan, pada tahap ini peneliti menjelaskan kepada siswa tentang strategi sebelum pembelajaran. Kegiatan kedua yaitu persiapan, pada tahap ini siswa diberi penjelasan tentang materi apa yang akan dipelajari pada hari ini. Kegiatan ketiga yaitu inisisasi dan akuisisi, pada tahap ini peneliti membagi menjadi beberapa kelompok untuk diskusi. Kegiatan keempat yaitu elaborasi, pada tahap ini peneliti mempersilahkan kepada siswa mempresentasikan kedepan kelas hasil diskusi dengan kelompoknya. Kegiatan kelima yaitu inkubasi dan memasukkan materi, pada tahap ini peneliti mejelaskan materi garis singgung lingkaran. Kegiatan keenam yaitu verifikasi dan pengecekan kepercayaan, pada tahap ini siswa menulis apa yang mereka 
pelajari dan yang dijelaskan oleh peneliti. Kegiatan ketujuh yaitu perayaan dan integrasi, pada tahap ini peneliti memberikan waktu kepada siswa untuk bertanya dan sharing kepada peneliti.

\section{HASIL DAN PEMBAHASAN}

Hasil uji coba melalui validasi soal diperoleh bahwa soal sebanyak 8 butir menyatakan bahwa soal berkriteria valid, jadi 8 soal tersebut digunakan untuk penelitian. kemudian dikelas eksperimen diberikan soal posttest dan diuji normalitas diperoleh nilai 0,191 jadi data tersebut berdistribusi normal karena $0,191>0,05$ jadi data tersebut berdistribusi normal. Setelah dilakukan uji normalitas kemudian dilakukan uji homogenitas diperoleh nilai 0,424 >0,05 jadi data tersebut memiliki varians yang homogen. Selanjutnya dilakukan uji one sample $t$ tes diperoleh nilai sig (2-tailed) $0,000<0,05$ artinya bahwa kemampuan rata-rata berfikir kreatif siswa lebih dari 70. Hasil uji one sample t test dapat dilihat pada Tabel 1 di bawah ini.

Tabel 1. Uji One-Sample Test

\begin{tabular}{lcccccc}
\hline & \multicolumn{5}{c}{ Test Value $=70$} \\
\cline { 2 - 6 } & $\mathrm{T}$ & Df & $\begin{array}{c}\text { Sig. (2- } \\
\text { tailed) }\end{array}$ & $\begin{array}{c}\text { Mean } \\
\text { Differenc }\end{array}$ & $\begin{array}{c}\text { 95\% Confidence } \\
\text { Interval of the } \\
\text { Difference } \\
\text { Lower }\end{array}$ \\
$\begin{array}{l}\text { Kemampuan berfikir } \\
\text { kreatif }\end{array}$ & 9.544 & 33 & .000 & 14.265 & 11.22 & 17.31 \\
\hline
\end{tabular}

Setelah dilakukan uji one sample $t$ test dilakukan uji $t$ untuk mencari rata-rata dari hasil uji t diperoleh nilai $0,001<0,05$ artinya terdapat perbedaan yang signifikan antara kemampuan siswa yang memperoleh pembelajaran secara konvensional dengan siswa yang memperoleh pembelajaran dengan model Brain-Based Learning Berbantuan Geogebra. Hasil uji t dapat dilihat pada Tabel 2 di bawah ini.

Tabel 2. Independent Samples Test

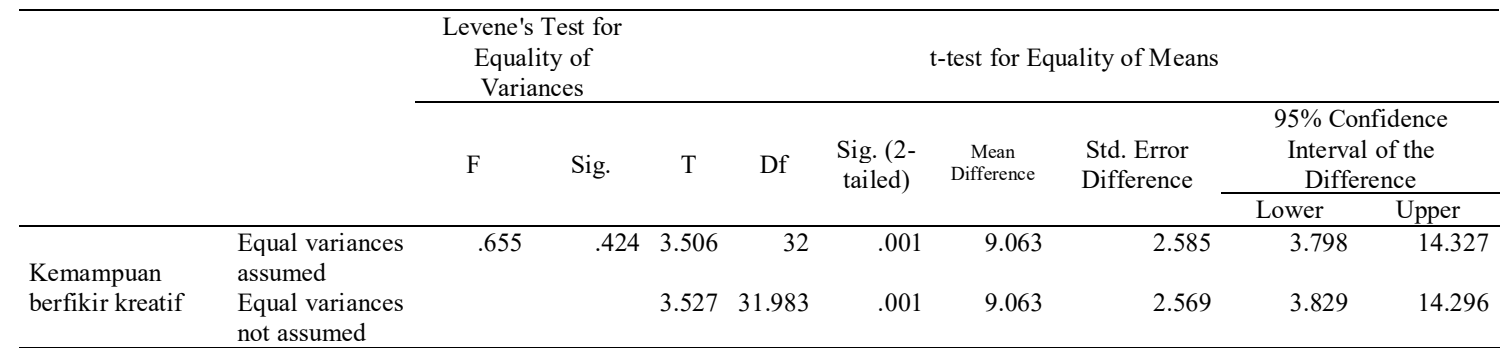

Berdasarkan hasil pretest diperoleh rata-rata skor untuk kelas eksperimen adalah 82,19 dan nilai rata-rata kelas kontrol adalah 81,67. Dari hasil skor pretest tersebut terlihat bahwa kemampuan awal siswa pada kedua kelas sampel tidak terlalu berbeda dan masih tergolong rendah. Selanjutnya dilakukan analisis terhadap kemampuan awal siswa, yang berarti kemampuan awal kedua kelas adalah sama. Kemudian pada kedua kelompok diberikan perlakuan yang berbeda yaitu pada kelas eksperimen menggunakan model pembelajaran BrainBased Learning berbantuan Geogebra dan kelas kontrol menggunakan model pembelajaran 
konvensional. Diakhir pembelajaran diberikan posttest untuk melihat kemampuan akhir siswa pada materi garis singgung lingkaran.

Kemampuan berfikir kreatif matematika siswa yang diajar dengan menggunakan strategi Brain-Based Learning berbantuan Geogebra lebih tinggi dari kemampuan berfikir kreatif matematika siswa dengan menggunakan pembelajaran konvensional. Hal ini didukung oleh penelitian sebelumnya yang dilakukan oleh Abdurrozak, Jayadinata dan Isrok'atun (2016), yang menyatakan bahwa terdapat peningkatan pembelajaran menggunakan model Brain-Based Learning dibandingkan dengan menggunakan model pembelajaran konvensional, hal ini dikarenakan peningkatan berfikir kreatif siswa dengan menggunakan model pembelajaran Brain-Based Learning sangat tinggi.

Dari hasil posttest terlihat bahwa kedua kelompok mengalami peningkatan kemampuan berfikir kreatif dalam menjawab soal yang signifikan. Dimana skor rata-rata posttest kelas eksperimen adalah 89,06 sedangkan skor rata-rata kelas kontrol adalah 80,00. Namun setelah dilakukan uji perbedaan kemampuan akhir kedua kelas eksperimen dan kelas kontrol, diperoleh bahwa nilai (sig 2-tailed) yaitu 0,001 <0,05, artinya terdapat perbedaan yang signifikan antara kemampuan berfikir kreatif matematika siswa yang memperoleh pembelajaran dengan menggunakan strategi Brain-Based Learning berbantuan Geogebra dengan kemampuan berfikir kreatif matematika siswa yang memperoleh pembelajaran dengan cara konvensional. Sehingga dapat disimpulkan bahwa siswa yang diberi perlakuan dengan menggunakan strategi Brain Based Learning berbantuan Geogebra lebih efektif terhadap pemahaman konsep dibandingkan dengan kelompok siswa yang diberi perlakuan dengan menggunakan model pembelajara konvensional pada materi garis singgung lingkaran di kelas VIII MTs An Nur Kedungtuban Kabupaten Blora.

Hal ini didukung oleh penelitian sebelumnya yang dilakukan oleh Hidayati dan Kurniati (2018), yang menyatakan bahwa siswa dapat mengeksplor pengetahuannya melalui Geogebra. Siswa yang dapat mengeksplor pengetahuannya akan mempunyai ilmu yang lebih luas. Kemampuan mengeksplore pengetahuan akan mengasah kreatifitas. Hal ini didukung oleh penelitian sebelumnya yang dilakukan oleh Wahyuni Dan Kurniawan (2018), yang menyatakan bahwa kemampuan berfikir kreatif memiliki kecenderungan untuk melatih siswa mengeluarkan ide-ide baru dalam proses pembelajaran. Penelitian ini juga didukung oleh Isman M. Nur (2016) yang menyatakan bahwa pembelajaran dengan bantuan komputer sangat baik diintegrasikan kedalam konsep-konsep matematika. Contohnya adalah pembelajaran menggunakan aplikasi Geogebra. Geogebra dapat digunakan pada saat mulai menggambar grafik dan membuat titiktitik jadi hal ini dapat mempermudah siswa dalam mengaplikasikan belajarnya dengan baik.

Hal ini terjadi karena kegiatan belajar-mengajar dengan pembelajaran Brain-Based Learning berbantuan Geogebra yang merupakan pembelajaran yang diselaraskan dengan cara kerja otak yang akan membuat siswa nyaman, rileks dan santai dalam belajar. Penggunaan Geogebra juga membantu siswa memahami konsep geometri pada garis singgung lingkaran denga baik. Hal ini didukung oleh penelitian sebelumnya yang dilakukan oleh Nur (2016), yang menyatakan bahwa kompetensi yang harus dimiliki siswa adalah kemampuan berfikir kreatif serta siswa tidak tergantung kepada orang lain untuk menyelesaikan suatu tugas. Salah satu upaya agar siswa mampu berfikir kreatif lebih tinggi adalah memberikan pembelajaran yang lebih menekankan pada keaktifan siswa. 


\section{SIMPULAN}

Simpulan dari penelitian ini adalah (1) rata-rata nilai kemampuan berfikir kreatif matematika siswa yang diajarkan menggunakan strategi Brain-Based Learning berbantuan Geogebra lebih dari KKM (70), (2) rata-rata nilai kemampuan berfikir kreatif matematika siswa yang diajarkan menggunakan strategi Brain-Based Learning berbantuan Geogebra lebih tingi daripada kemampuan berfikir kreatif matematika siswa dengan menggunakan cara konvensional.

Saran dari penelitian ini adalah (1) saat mengajar guru disarankan menggunakan laboran, (2) guru disarankan mengenalkan Siswa terlebih dahulu tentang komputer sebelum pembelajaran menggunakan Geogebra, (3) saat mengajar guru memerlukan LCD supaya mempermudah guru menjelaskan dan mengajari siswa cara mengoperasika aplikasi Geogebra.

\section{DAFTAR PUSTAKA}

Hidayati, D.W., \& Kurniati, L. 2018. The Influence Of Self Regulate Learning To Mathematics Critical Thinking Ability On 3D-Shapes Geometry Learning Using Geogebra. JIPM (Jurnal Ilmiah Pendidikan Matematika), $\quad$ 7(1). journal.unipma.ac.id/index.php/jipm/article/view/2965

Isman M. Nur. 2016. Pemanfaatan Program Geogebra Dalam Pembelajaran Matematika. Delta-Pi: Jurnal Matematika Dan Pendidikan Matematika, 5(1) http://ejournal.unkhair.ac.id/index.php/deltapi/article/viewFile/236/188

Kusumah, Y.S, 2003. Desain dan Pengembanagan Bahan Ajar Matematika Interaktif Berbasiskan Teknologi Komputer. Makalah terdapat Pada Seminar Proceding National Seminar on Science and Math Education. Seminar diselenggarakan oleh FMIPA UPI Bandung bekerja sama dengan JICA

Lestari, K.E. 2014. Implementasi Braind Brain Based Learning untuk meningkatkan kemampuan koneksi dan kemampuan berfikir serta motivasi belajar siswa SMP. Judika (Jurnal pendidikan UNSIKA), 2(1)

Nur, I.R.D. 2016. Meningkatkan Kemampuan Berfikir Kreatif Matematis Da'n Kemandirian Belajar Siswa Dengan Menggunakan Model Pembelajaran Brain-Based Learning. JUDIKA (Jurnal Pendidikan Matematika), 4(1) https://journal.unsika.ac.id/index.php/judika/article/view/234

Putra, H. D \& Purwasih, R. 2015. Meningkatkan prestasi belajar dan keaktifan mahasiswa melalui project Based Learning. Jurnal ilmiah UPT P2M STKIP Siliwangi, No. 2(2). https://journal.unnes.ac.id/nju/index.php/kreano/article/view/12473/7947

Rakhmad, J. 2005. Belajar Cerdas: Belajar berbasis otak. Bandung: mizan Learning Center (MLC)

Ruseffendi. 2005. Dasar-dasar Penelitian Pendidikan Dan Bidang Non- eksakta, Bandung: Tarsito

Wahyuni, A., \& Kurniawan, P. 2018. Hubungan Kemampuan Berfikir Kreatif Terhadap Hasil Belajar Mahasiswa. Jurnal Teori Dan Terapan Matematika. 17(2). https://ejournal.unisba.ac.id/index.php/matematika/article/view/4114 